\title{
Silencing of S100A4, a metastasis-associated protein, in endothelial cells inhibits tumor angiogenesis and growth
}

\author{
Takahiro Ochiya • Keizo Takenaga • \\ Hideya Endo
}

Received: 12 March 2013/Accepted: 22 July 2013/Published online: 9 August 2013

(C) The Author(s) 2013. This article is published with open access at Springerlink.com

\begin{abstract}
Endothelial cells express S100A4, a metastasisassociated protein, but its role in angiogenesis remains to be elucidated. Here we show that knockdown of S100A4 in mouse endothelial MSS31 cells by murine specific small interference RNA (mS100A4 siRNA) markedly suppressed capillary-like tube formation in vitro, in early stage after the treatment, along with down- and up-regulation of some of the pro-angiogenic and anti-angiogenic gene expression, respectively. Of particular note is that intra-tumor administration of the mS100A4 siRNA in a human prostate cancer xenograft significantly reduced tumor vascularity and resulted in the inhibition of tumor growth. These findings show that S100A4 in endothelial cells is involved in tube formation, and suggest its potential as a molecular target for inhibiting tumor angiogenesis, which warrants further development of endothelial S100A4-based strategies for cancer treatment.
\end{abstract}

Keywords Angiogenesis $\cdot$ S100A4 $\cdot$ siRNA ·

Endothelial cells · Tumor · Therapy

Electronic supplementary material The online version of this article (doi:10.1007/s10456-013-9372-7) contains supplementary material, which is available to authorized users.

\section{T. Ochiya}

Division of Molecular and Cellular Medicine,

National Cancer Center Research Institute,

5-1-1, Tsukiji, Chuo-ku,

Tokyo 104-0045, Japan

K. Takenaga

Department of Life Science, Faculty of Medicine,

Shimane University, 89-1 Enya, Izumo 693-8501, Japan

H. Endo $(\bowtie)$

Institute of Medical Science, University of Tokyo, 4-6-1 Shirokanedai, Minato-ku, Tokyo 108-8639, Japan

e-mail: endoh@ims.u-tokyo.ac.jp

\section{Introduction}

S100A4, a member of the S100 family of EF-hand calcium-binding proteins, is involved in the regulation of a variety of biological processes, including tumor progression and metastasis [1]. It is highly expressed in various metastatic tumor cells and its elevated expression is associated with the poor prognosis of different types of human cancers [2-7]. The involvement of S100A4 in the promotion of tumor metastasis has been demonstrated by several approaches [8-11]. Furthermore, recent studies on mice that lack the S100A4 gene [12], and on mice carrying tumor cells subjected to siRNA-mediated S100A4-downregulation [13-18], have shown suppression of tumor development and metastasis formation. Although the precise mechanism by which S100A4 stimulates invasion and metastasis remains unknown, an extracellular role for S100A4 suggested by studies showing the secretion of S100A4 by cancer cells and the presence of S100A4 in the serum of cancer patients is intriguing [19]. In fact, the exogenous addition of S100A4 stimulates endothelial cell motility in vitro [20] and induces corneal neovascularization [19] and metastasis formation in vivo [21]. On the other hand, little is known about the effect of endothelial S100A4 on angiogenesis. We previously reported that S100A4 is expressed in both tumor cells, and endothelial cells [22, 23]. Although endothelial cells have not been shown to secrete S100A4, and its biological function in these cells is unknown, the endothelial S100A4 may be pertinent for the regulation of tumor angiogenesis and metastasis, and thus an attractive target for cancer therapy.

In this study, we used siRNA-mediated depletion and DNA microarray analysis to investigate the function of S100A4 in endothelial cells. Furthermore, the effect of S100A4 knockdown on angiogenesis and tumor growth 
was examined in a xenograft cancer model. The results suggest that S100A4 in endothelial cells is involved in tube formation and thus siRNA-mediated inhibition of endothelial S100A4 could provide an effective anti-tumor RNAi medicine.

\section{Materials and methods}

Cell culture

We cultured mouse endothelial cells (MSS31) [22, 24-26], human prostate carcinoma cells expressing a firefly luciferase gene (PC-3M-Luc C6, purchased from Caliper LifeSciences) [27], mouse melanoma cells (B16-BL6, whose origin and properties were described by Dr. Fidler [28], were a gift of Dr. S. Taniguchi, Shinsyu University Graduate School of Medicine) [29] and Lewis lung carcinoma cells (P29) [30] in DMEM supplemented with $10 \%$ FBS.

siRNA preparation

Synthetic 21-nt RNAs were purchased from Ambion/Life Technologies (Carlsbad, CA, USA). The murine S100A4 siRNA (mS100A4 siRNA) sequence was 5'-UGA ACA AGA CAG AGC UCA Att- $3^{\prime}$ (sense) and $5^{\prime}$-UUG AGC UCU GUC UUG UUC Att-3' (antisense). AllStars negative control siRNA (QIAGEN, Hilden, Germany) was used as a negative control.

Transfection of siRNA in vitro

After $48 \mathrm{~h}$ of siRNA transfection using DharmaFECT No.1 (GE Healthcare, Waukesha, WI, USA), MSS31 cells were seeded on ECM-gel (SIGMA-Aldrich, St. Louis, MO, USA) thin-coated center-well dishes $(60 \mathrm{~mm}$, BD Falcon, Franklin Lakes, NJ, USA) at a cell density of $4 \times 10^{4}$ cells $/ \mathrm{cm}^{2}$ and cultured in the presence of $50 \mathrm{ng} / \mathrm{ml}$ HGF (PeproTech, Rocky Hill, NJ, USA). Capillary formation was assessed after $16 \mathrm{~h}$ of Matrigel culture [31]. RNA samples were extracted from transfected cells before seeding for realtime PCR analysis of S100A4 mRNA, using ISOGEN and platinum SYBR green qPCR superMix-UDG (Invitrogen/ Life Technologies).

Cell adhesion and wound healing assay

Migration ability was determined using a cell adhesion and a wound healing assay. After $48 \mathrm{~h}$ of S100A4 siRNA or negative control siRNA transfection, MSS31 cells was plated on 24-muti-well plate (Nunc, Thermo Scientific, Japan) at a cell density of $4 \times 10^{4}$ cells $/ \mathrm{cm}^{2}$ and then counted the number of adhered cells at $30 \mathrm{~min}, 1$ and $3 \mathrm{~h}$.
siRNA-transfected MSS31 cells were grown on $60 \mathrm{~mm}$ plates. After the cells reached sub-confluence, the cells were pretreated with mitomycin $\mathrm{C}(10 \mu \mathrm{g} / \mathrm{ml})$ for $30 \mathrm{~min}$ and then the cells were wounded by scraping the monolayer and grown in medium for $16 \mathrm{~h}$. The width of the wound was measured. Three different locations were visualized and photographed under a phase-contrast inverted microscope (ECLIPSE1000, Nikon, NY, USA). Data was represented as a percent of wound healing.

\section{Real-time PCR analysis}

Total RNA was extracted from cells by ISOGEN (Nippon Gene, Tokyo, Japan) and treated with DNase I (Takara, Otsu, Japan). Five $\mu \mathrm{g}$ of total RNA was used to produce cDNAs with oligo (dT) 12 primer by superscript III RNA polymerase (Invitrogen/Life Technologies). cDNA was diluted five-fold and used for quantitative PCR. For quantitation, aliquots of $5 \mu \mathrm{l}$ of cDNA samples were subjected to quantitative PCR in $50 \mu 1$ reactions using Platinum Quantitative PCR SuperMix-UDG (Invitrogen/Life Technologies) and Assays-on-Demand TaqMan primers/ probe sets (Applied Biosystems, Foster City, CA, USA) specific for target genes (Supplementary Table S1). Reactions were carried out using the ABI PRISM 7700 sequence detection System (Applied biosystems). The reactions were incubated at $50{ }^{\circ} \mathrm{C}$ for $2 \mathrm{~min}$, then heated to $95{ }^{\circ} \mathrm{C}$ for 2 min followed by 45 cycles of $30 \mathrm{~s}$ at $95{ }^{\circ} \mathrm{C}, 15 \mathrm{~s}$ at $60{ }^{\circ} \mathrm{C}$, and $20 \mathrm{~s}$ at $72{ }^{\circ} \mathrm{C}$. The GAPDH gene and $\beta$-actin gene were used as an internal control.

\section{Microarray analysis}

RNA quantity and quality were determined using a Nanodrop ND-1000 spectrophotometer (Thermo Fisher Scientific Inc., Waltham, MA, USA) and an Agilent Bioanalyzer (Agilent Technologies, Palo Alto, CA, USA), as per manufacturer's instructions. Total RNA was amplified and labeled with Cyanine 3 (Cy3) using Agilent Low Input Quick Amp Labeling Kit, one-color (Agilent Technologies) according to the manufacturer's instructions. Briefly, $100 \mathrm{ng}$ of total RNA was reversed transcribed to doublestrand cDNA, using a poly dT-T7 promoter primer. Primer, template RNA and quality-control transcripts of known concentration and quality were first denatured at $65{ }^{\circ} \mathrm{C}$ for $10 \mathrm{~min}$, then incubated for $2 \mathrm{~h}$ at $40{ }^{\circ} \mathrm{C}$ with $5 \mathrm{X}$ first strand Buffer, 0.1 M DTT, $10 \mathrm{mM}$ dNTP mix, and AffinityScript RNase Block Mix. The AffinityScript enzyme was then inactivated at $70{ }^{\circ} \mathrm{C}$ for $15 \mathrm{~min}$. cDNA products were used as templates for in vitro transcription to generate fluorescent cRNA. cDNA products were mixed with a transcription master mix in the presence of T7 RNA polymerase and $\mathrm{Cy} 3$ labeled-CTP and incubated at $40{ }^{\circ} \mathrm{C}$ for $2 \mathrm{~h}$. Labeled 
cRNAs were purified using QIAGEN's RNeasy mini-spin columns and eluted in $30 \mu \mathrm{l}$ of nuclease-free water. After amplification and labeling, cRNA quantity and cyanine incorporation were determined using a Nanodrop ND-1000 spectrophotometer and an Agilent Bioanalyzer. For each hybridization, $1.65 \mu \mathrm{g}$ of $\mathrm{Cy} 3$ labeled cRNA was fragmented, and hybridized at $65{ }^{\circ} \mathrm{C}$ for $17 \mathrm{~h}$ on an Agilent Mouse GE 4x44K v2 Microarray (Design ID: 026655). After washing, microarrays were scanned using an Agilent DNA microarray scanner. Intensity values of each scanned feature were quantified using Agilent feature extraction software version 10.7.3.1, which performs background subtractions. Features that were flagged as having no errors (present flags) were used and features that were not positive, not significant, not uniform, or not above the background level were excluded. Features that were saturated and any population outliers (marginal and absent flags) were also excluded. Normalization was performed using Agilent GeneSpring GX version 11.0.2. (per chip: normalization to 75 percentile shift; per gene: normalization to median of all samples). There were 39,429 probes on the Agilent Mouse GE 4x44K v2 Microarray (Design ID: 026655), excluding control probes. The altered transcripts were quantified using the comparative method. A $\geq$ twofold change in signal intensity was designated as a significant difference in gene expression.

\section{Animals}

Animal experiments were performed in compliance with the guidelines of the Institute for Laboratory Animal Research at the National Cancer Center Research Institute.
The mice were maintained under specific pathogen-free conditions with a 12-h light-dark cycle.

Study of xenografted tumors

Eight- to 11-week-old male athymic nude mice (CLEA Japan, Osaka, Japan) were used for all experiments. Anesthetized animals were subcutaneously injected with $3 \times 10^{6}$ PC-3M-Luc C6 cells in $100 \mu$ sterile Dulbecco's PBS [30]. Nine days after subcutaneous inoculation of PC3M-Luc C6 cells into mice (hereinafter referred to as day 1), tumors were treated twice with $50 \mu \mathrm{g}$ siRNA/atelocollagen complex (day 1 and 3). After the treatment, tumor volume was measured at day 9,12 , and 15 . Tumor size was measured with calipers and tumor volume was calculated by $a b^{2} / 2$, where $a$ and $b$ are the lengths of the long and short axes, respectively. Number of animals was 4 in each group and the experiment was performed twice.

Imaging of tumor angiogenesis

Day 9 after the siRNA treatment, signals of AngioSenseIVM-750 were measured using fluorescence molecular tomography (FMT, VisEn Medical/PerkinElmer Inc., Waltham, MA, USA). AngioSense-IVM-750 is a $250 \mathrm{kDa}$ macromolecule that freely circulates while staying confined to the intravascular space. Relative value of angiogenesis of mS100A4 siRNA-treated tumor was measured when the negative siRNA control was set to 1.0 and the data was represented as relative angiogenesis. Blood vessels in tumors monitored by Angiosence day 9 after the siRNA treatment, tumor vessels were also visualized using
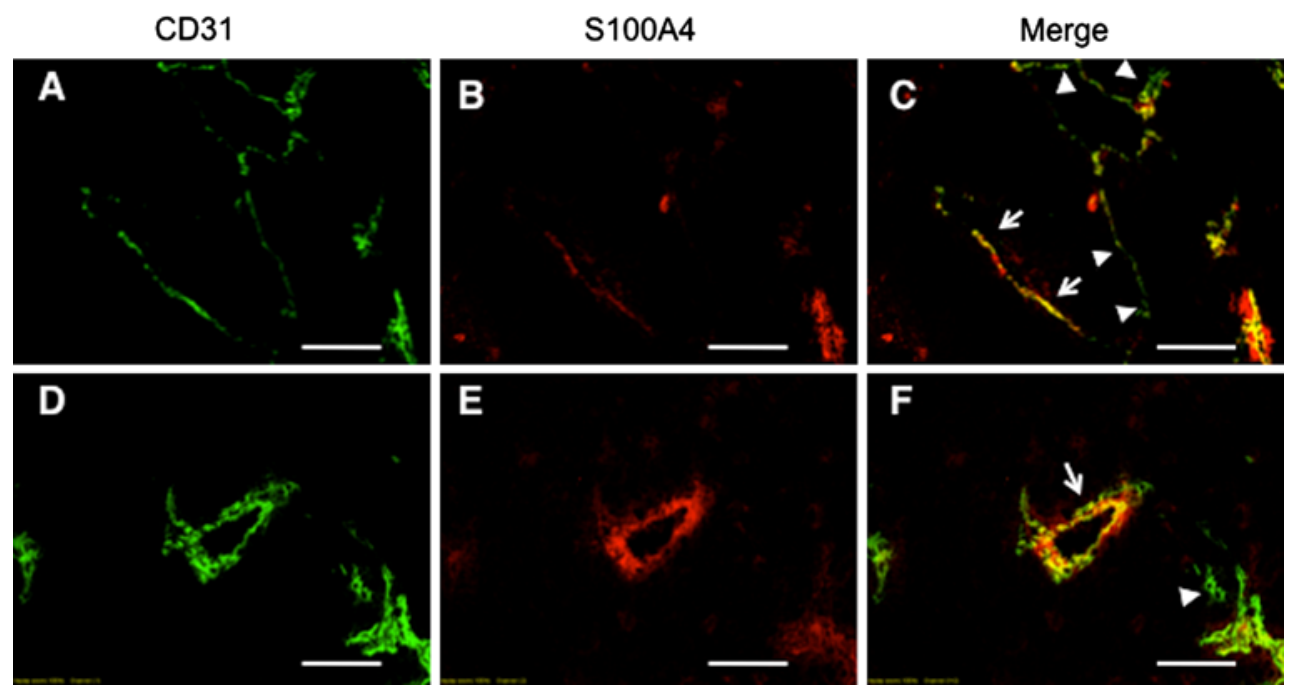

Fig. 1 S100A4 expression in endothelial cells of intratumoral vessels. B16-BL6 cells were injected subcutaneously into C57BL/6 mice. Two frozen sections of the tumor tissue were doubleimmunostained with anti-CD31 antibody (a, d) and anti-S100A4 antibody (b, e). Merged imaged are also shown (c, f). Arrows and arrowheads in $\mathbf{c}$ and $\mathbf{f}$ indicate the examples of $\mathrm{CD} 31^{+} \mathrm{S} 100 \mathrm{~A} 4^{+}$and $\mathrm{CD} 31^{+} \mathrm{S} 100 \mathrm{~A} 4^{-}$microvessels, respectively. Bars $200 \mu \mathrm{m}$ 
AngioSense-IVM-680 (ViSen medical) by intravenous administration of $50 \mu \mathrm{l}$ per mouse. AngioSense-IVM-680 is a near-infrared labeled fluorescent macromolecule that remains localized in the vasculature for extended periods of time and enables imaging of blood vessels and angiogenesis. Fifteen min after the dye administration, the vessel
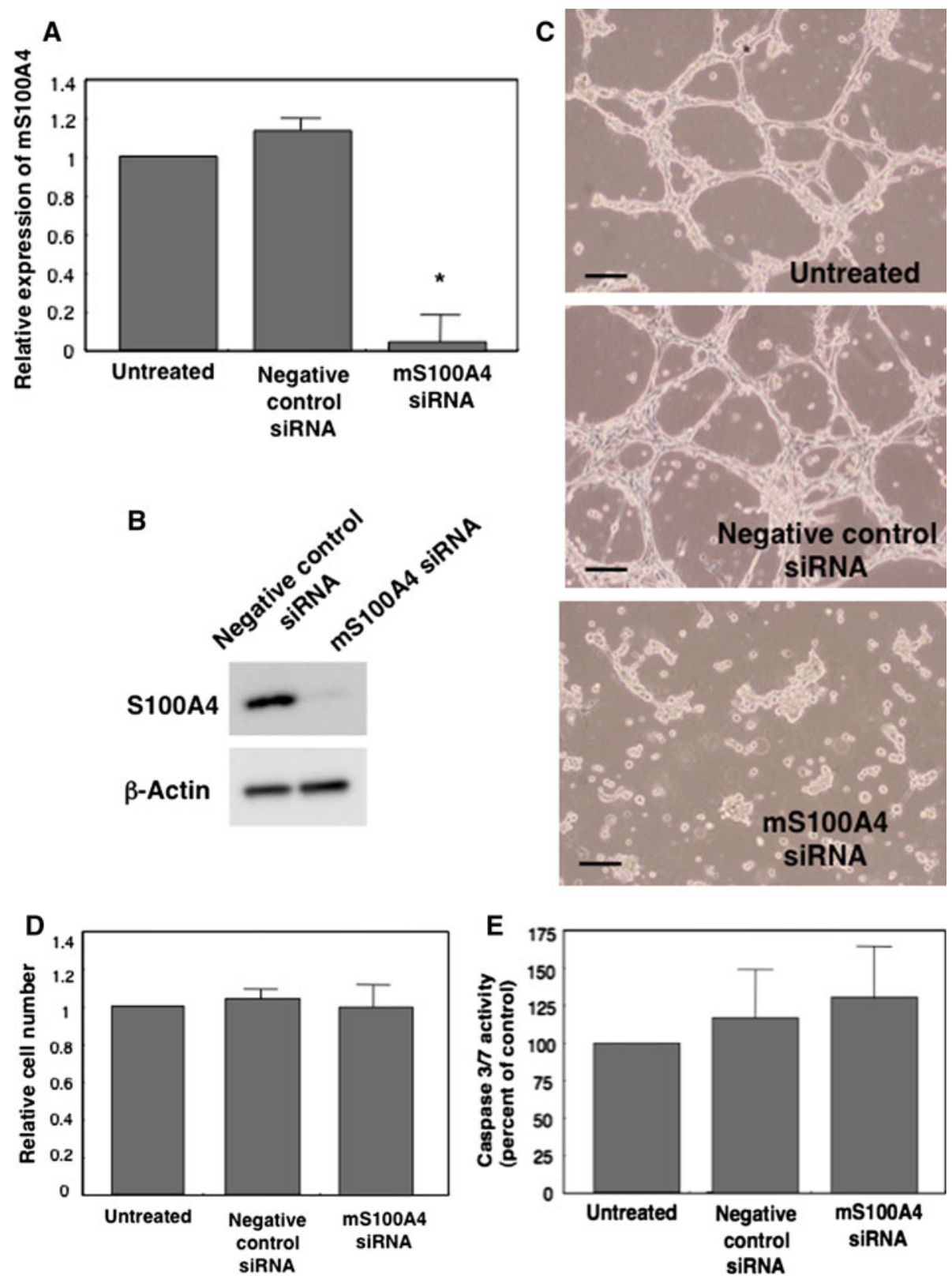

Fig. 2 Anti-angiogenesis activity of S100A4 siRNA in vitro. MSS31 cells were transfected with murine S100A4 siRNA (mS100A4 siRNA) or control siRNA. Two days after transfection, $9.9 \times 10^{4}$ MSS31 cells were seeded on ECM-gel thin-coated center-well dishes. RNA samples were extracted from transfected cells before seeding for real-time PCR analysis of S100A4 mRNA. HGF-induced capillary formation was assessed $16 \mathrm{~h}$ after Matrigel culture. a Relative expression of $\mathrm{mS100A} 4$ by real-time PCR analysis. $* P=0.01$. b Western blot analysis of the expression of S100A4 in cells $24 \mathrm{~h}$

after siRNA transfection. Rabbit polyclonal anti-S100A4 antibody (Abcam, ab27957) and rabbit monoclonal anti- $\beta$ actin antibody (Millipore, clone C4/MAB1501) were used. c Tube formation $16 \mathrm{~h}$ after siRNA treatment. Top, untreated control cells; middle, cells transfected with negative control siRNA; bottom, cells transfected with mS100A4 siRNA. Scale bars represent $50 \mu \mathrm{m}$. d Cell growth inhibition by mS100A4 siRNA. Cell growth was monitored by cell number analysis $16 \mathrm{~h}$ after siRNA transfection. e Caspase-3/7 activity. The activity was measured $16 \mathrm{~h}$ after siRNA transfection 


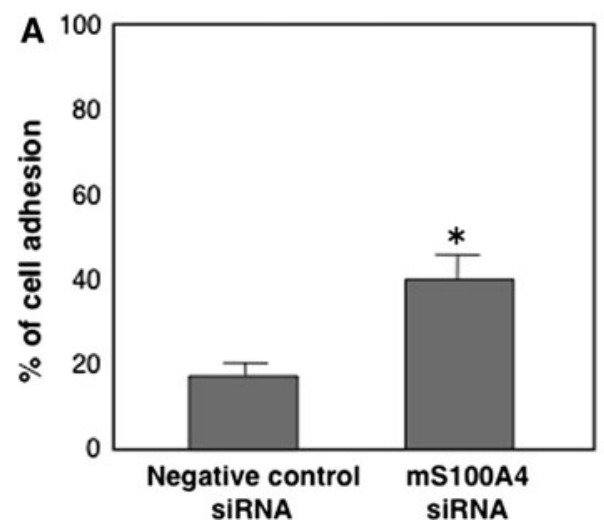

Fig. 3 S100A4-mediated cell adhesion and migration. a Cell adhesion assay was performed on MSS31 cells treated with S100A4 siRNA or negative control siRNA (N.C. siRNA). Phase-contrast photograph of adhered cells was recorded at $30 \mathrm{~min}, 1$ and $3 \mathrm{~h}$ after cell plating. Percent of cell adhesion at $30 \mathrm{~min}$ was exhibited. S100A4 siRNA-treated cells: $41 \pm 5 \%$; negative control siRNAtreated cells: $18 \pm 2 \%, P=0.0017$. b Wound healing assay was

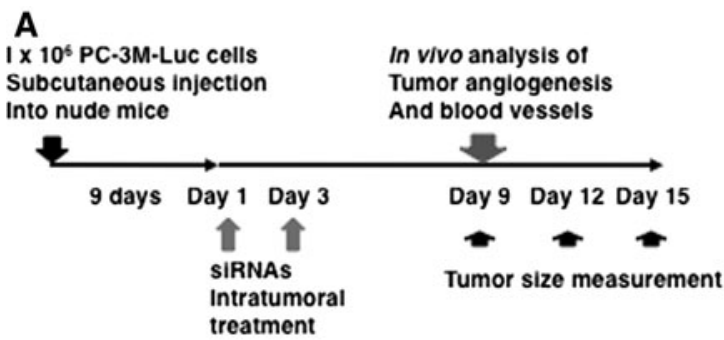

\section{Negative control siRNA}

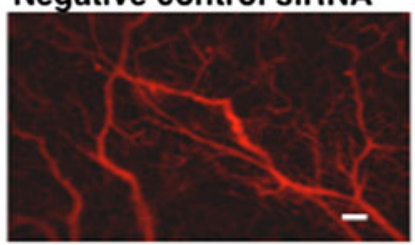

mS100A4 SIRNA

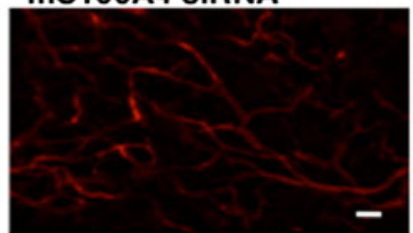

Fig. 4 Inhibition of tumor angiogenesis by mouse S100A4-specific siRNA (mS100A4 siRNA). a Schematic representation of in vivo animals experiments. PC-3M-Luc C6 cells $\left(1 \times 10^{6}\right.$ cells $)$ were subcutaneously inoculated into 9 -week-old male athymic nude mice. Nine days after subcutaneous inoculation of PC-3M-Luc C6 cells into mice (hereinafter referred to as day 1), tumors were treated twice with $50 \mu \mathrm{g}$ siRNA/atelocollagen complex (day 1 and 3). Number of animals in each group was 4. b At day 9, angiogenesis in tumors was monitored with the administration of the fluorescence detection agent,

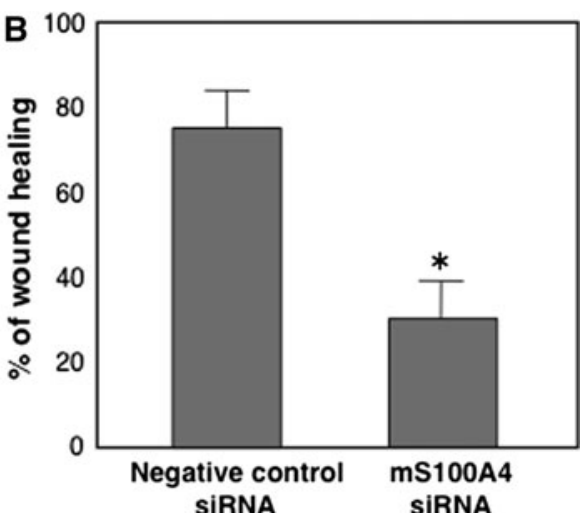

performed on MSS31 cells treated with S100A4 siRNA or N.C. siRNA. The width of the wound was measured after $16 \mathrm{~h}$ of the cell wounding by scraping the monolayer. Three different locations were visualized and photographed under a phase-contrast inverted microscope (ECLIPSE1000, Nikon). Data was represented as a percent of wound healing. S100A4 siRNA-treated cells: $30 \pm 7 \%$; negative control siRNA-treated cells: $76 \pm 9 \%, P=0.0003$

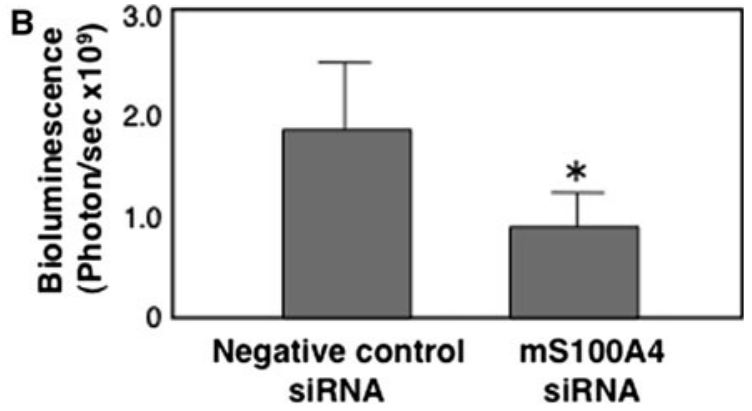

AngioSence-IVM-750, by FMT. Photon count per sec of mS100A4 siRNA-treated and the negative control siRNA-treated tumors were exhibited. The animal experiment was performed twice $(\mathrm{N}=4$ in each experiment). $* P=0.05$. c At day 9 , angiogenesis in tumors monitored by Angiosence. Vessels were visualized using AngioSense-IVM-680 (ViSen medical) by intravenous administration of $50 \mu \mathrm{l}$ per mouse. Fifteen min after the dye administration, the vessel images were acquired by using Olympus OV110 (Olympus, Japan). Scale bars represent $100 \mu \mathrm{m}$ 


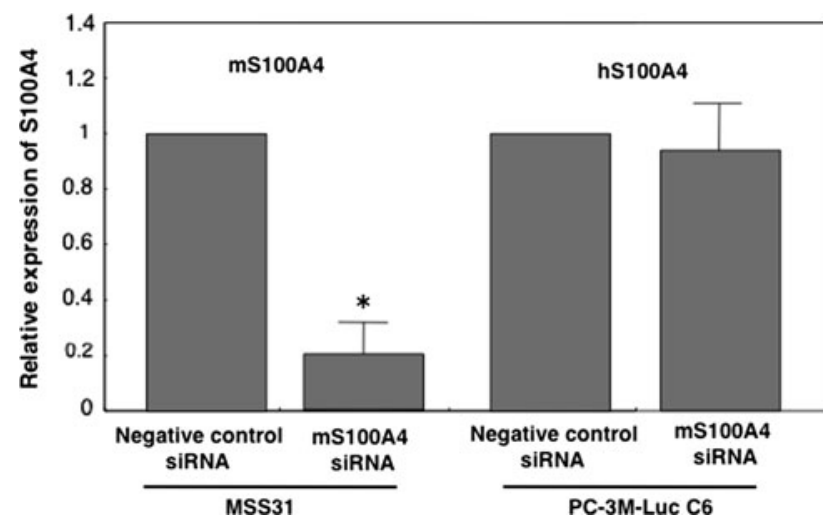

Fig. 5 mS100A4 siRNA specifically inhibited expression of mS100A4, but not human S100A4 (hS100A4). MSS31 (murine) and PC-3M-Luc C6 (human) cells were transfected with murine S100A4 siRNA (mS100A4 siRNA) and negative control siRNA. Two days after transfection, RNA samples were extracted from transfected cells and subjected to real-time PCR analysis of S100A4 mRNA. $* P=0.05$

images were acquired by using Olympus OV110 (Olympus, Japan).

Atelocollagen-mediated siRNA delivery in vivo

To prepare the siRNA/atelocollagen complex, equal volumes of atelocollagen (1.0\% in PBS at $\mathrm{pH} 7.4$, Koken Co., Ltd, Tokyo, Japan) and siRNA solution were combined and mixed by rotation for $20 \mathrm{~min}$ at $4{ }^{\circ} \mathrm{C}$. The final concentration of atelocollagen was $0.5 \%$. Individual mice were injected with $200 \mu \mathrm{l}$ of atelocollagen containing $50 \mu \mathrm{g}$ of mS100A4 siRNA or non-silencing control siRNA/atelocollagen by intratumoral injection (negative control siRNA).

Measurement of caspase-3/7 activity in vitro

Caspase-3/7, which plays key effector roles in apoptosis, was determined with the Apo-ONE Homogeneous caspase$3 / 7$ assay (Promega) according to the manufacturer's instructions. Cells were incubated with the Apo-ONE caspase-3/7 assay reagent for $1.5 \mathrm{~h}$ at room temperature, and the fluorescence was then measured at $485 \mathrm{Ex} / 535 \mathrm{Em}$ with a Wallac multi-label counter.

\section{Double-immunostaining of CD31 and S100A4}

B16-BL6 cells $\left(1 \times 10^{6}\right.$ cells $)$ were injected subcutaneously into C57BL/6 mice (6-7 weeks of age, Nippon SLC, Shizuoka, Japan). Fourteen days after the injection, tumor tissues were removed, embedded in a tissue-freezing medium, and then cut into $5 \mu \mathrm{m}$-thick sections. For doubleimmunostaining of CD31 and S100A4, tissue sections were fixed in acetone for $10 \mathrm{~min}$. The samples were blocked with PBS containing $0.1 \%$ bovine serum albumin and $2 \%$ goat serum and then incubated with a mixture of rat antimouse CD31 antibody (Pharmingen, San Diego, CA, USA) and rabbit anti-S100A4 antibody [23]. The sections were washed three times with PBS, and incubated with a mixture of TRITC-labeled goat anti-mouse IgG and FITC-labeled goat anti-rabbit IgG. After rinsing with PBS, the sections were mounted in $50 \%$ glycerol in PBS containing $1 \mathrm{mg} / \mathrm{ml}$ p-phenylenediamine to inhibit photobleaching, and were observed under a confocal laser scanning microscope (Fluoview, Olympus, Tokyo, Japan). Using NIH Image $\mathbf{J}$ $1.42 \mathrm{q}$ software (http://rsb.info.nih.gov/ij), a ratio of S100A4 pixel values to $C D 31$ pixel values was calculated for each image $(n=6)$ for determination of S100A4/CD31 double-positive areas.

\section{Statistical analyses}

Statistical analyses were conducted using Student's $t$ test for in vitro screening of cell capillary morphogenesis and proliferation and evaluation of in vivo angiogenesis. A $P$ value of 0.05 or less was considered significant.

\section{Results}

Inhibition of capillary formation in endothelial cells by S100A4 siRNA

We first examined whether endothelial cells of tumor microvessels express S100A4. For this, we immunostained the microvessels in tumor tissues formed by B16-BL6 melanoma cells that express little S100A4 with anti-CD31 and anti-S100A4 antibody (Fig. 1, Supplementary Fig. S1). The results showed that there were S100A4-positive and -negative $\mathrm{CD} 1^{+}$endothelial cells (arrows and arrowheads in Fig. 1, panels $\mathrm{c}$ and $\mathrm{f}$ ). Quantification of each $\mathrm{S} 100 \mathrm{~A} 4^{+}$and $\mathrm{CD} 31^{+}$area in double-stained tissue sections showed that approximately half $(49.3 \pm 29.5 \%$, $\mathrm{n}=6$ ) of $\mathrm{CD} 31^{+}$endothelial cells was S100A4-positive. These results suggest that there exist subpopulations of endothelial cells in tumors that might, or might not, be primed for angiogenesis. This prompted us to examine the role of S100A4 in angiogenesis and, to this end, we tested the effect of siRNA-mediated depletion of S100A4 on capillary formation in mouse endothelial MSS31 cells. Specifically, murine S100A4 siRNA (mS100A4 siRNA) completely blocked S100A4 expression in MSS31 cells at both the mRNA and protein levels (Fig. 2a, b). Hepatocyte growth factor (HGF)-induced capillary formation was assessed $16 \mathrm{~h}$ after Matrigel culture [2]. siRNA-induced knockdown of mS100A4 resulted in the inhibition of HGF- 
Table 1 Area of vessels in animals

\begin{tabular}{llr}
\hline & Volume of tumor $\left(\mathrm{mm}^{3}\right)$ & Area of vessels $\left(\mathrm{mm}^{2}\right)$ \\
\hline Negative control siRNA & $36.3 \pm 3.1$ & $0.129 \pm 0.001$ \\
mS100A4 siRNA & $31.5 \pm 5.0$ & $0.053 \pm 0.0008^{*}$ \\
\hline
\end{tabular}

Nine days after subcutaneous inoculation of human prostate cancer cells (PC-3M-Luc C6) into mice (hereinafter referred to as day 1), tumors were treated twice with $50 \mu \mathrm{g}$ siRNA/atelocollagen complex. After the treatment angiogenesis images were acquired at day 9 using Olympus OV110 and vessels were visualized using AngioSense-IVM-680 (ViSen medical) by intravenous administration. Area of vessels was measured by Image $\mathbf{J}$ (Olympus). Number of animals was 4 in each group

$* P<0.05$

Table 2 Tumor volume in animals

\begin{tabular}{llll}
\hline Volume of tumor $\left(\mathrm{mm}^{3}\right)$ & Day 9 & Day 12 & Day 15 \\
\hline Negative control siRNA & $36.3 \pm 3.1$ & $39.7 \pm 2.6$ & $44.8 \pm 1.8$ \\
mS100A4 siRNA & $31.5 \pm 5.0$ & $30.2 \pm 3.8$ & $27.1 \pm 2.2 *$
\end{tabular}

Nine days after subcutaneous inoculation of human prostate cancer cells (PC-3M-Luc C6) into mice (hereinafter referred to as day 1), tumors were treated twice with $50 \mu \mathrm{g}$ siRNA/atelocollagen complex twice (day 1 and 3). After the treatment tumor volume was measured at day 9,12 , and 15 . Number of animals was 4 in each group

$* P<0.05$

induced capillary formation in MSS31 cells in vitro, while control siRNA showed no inhibitory effect when compared to untreated controls (Fig. 2c). Additionally, suppression of cell growth of MSS31 cells was not detectable within $16 \mathrm{~h}$ of mS100A4 siRNA treatment (Fig. 2d) and the analysis of caspase $3 / 7$ activity did not show caspase-dependent apoptotic cell death (Fig. 2e), excluding a possibility that the inhibition of tube formation by the siRNA is non-specific effect. These results indicate that S100A4 is important for tube formation of endothelial cells. In addition, cell adhesion and cell migration assay was performed. As shown in Fig. 3a, cell adhesion was significantly enhanced by inhibition of S100A4 by S100A4 siRNA as compared to N.C. siRNA $(P=0.0017)$. Wound healing assay revealed that knockdown of S100A4 inhibited cell migration significantly $(P=0.0003)$ in Fig. 3b. Taken together, these results of multiple angiogenesis assay clearly indicate that S100A4 is significantly involved in angiogenesis.

\section{Inhibition of tumor angiogenesis by S100A4 siRNA}

To examine the effect of mS100A4 siRNA on tumor angiogenesis, PC-3M-Luc C6 cells were inoculated into athymic mice. Nine days after the injection (hereinafter referred to as day 1), tumors were treated twice with $50 \mu \mathrm{g}$ siRNA/atelocollagen complex intratumorally. After the treatment, tumor angiogenesis was measured at day 9 (Fig. 4a). Administration of a fluorescent imaging agent revealed a strong inhibition of tumor angiogenesis by mS100A4 siRNA (Fig. 4b), without a discernible reduction in tumor volume (Supplementary Fig. S3). The mS100A4 siRNA was designed to inhibit specifically murine S100A4 expression, and not human S100A4 in PC-3M-Luc C6 cells (Fig. 5). Thus, these findings showed that endothelial cells were the primary targets of mS100A4 siRNA, not human tumor cells. Additionally, AngioSense analysis demonstrated that vessel formation in tumors was clearly inhibited by mS100A4 siRNA (Fig. 4c, Supplementary Fig. S2, Table 1). Thus, the results indicate that mS100A4 siRNA acts directly upon and inhibits host angiogenesis. We also found that mS100A4 siRNA inhibits tumor growth, with a significant reduction in tumor volume by day 15 (Table 2).

Microarray analysis of angiogenesis-related gene expression in S100A4 knockdown endothelial cells

To gain mechanistic insight into the above observations, we compared the gene expression profiles of MSS31 cells treated with either mS100A4 siRNA or control siRNA. Unsupervised hierarchical cluster analysis was performed on 745 angiogenesis-related genes (Supplementary Fig S4,Supplementary Table S1, Supplementary excel file). The analyses showed that significant alterations in angiogenesis-related gene expression occurred in the S100A4 siRNA treatment group, suggesting that S100A4 plays a role in controlling angiogenesis. Genes with significant alterations (twofold or more) in expression level are listed in Table 3. These genes were validated by qRT-PCR analysis (Fig. 6a, b). Genes in mS100A4 knockdown cells with lower expression levels included angiogenesis-associated genes, such as aquaporin-1 (aqp1) [32], fibroblast growth factor 18 (fgfl8) [33], resistin (retn) [34], mitogenactivated protein kinase kinase kinase 5 (map $3 k 5$ ) [35], thymus cell antigen (thyl) [36], forkhead box O6 (foxo6) [37], heparan sulfate 6-O-sulfotransferase 1 (hs6stl) [38] and matrix metalloproteinase 3 ( $\mathrm{mmp} 3$ ) [39], which are widely expressed in cardiovascular tissue. They induce endothelial migration and microvessel formation, which are central to diverse biological phenomena including angiogenesis, wound healing, and metastasis. Genes in mS100A4 knockdown cells with higher expression levels included anti-angiogenesis genes such as cyclin-dependent 
kinase inhibitor 1A (cdknla) [40], thrombospondin 1 (thbsl) [41], and sprouty homolog 4 (spry4) [42]. Taken together, microarray analysis validated the function of endothelial S1004A in angiogenesis.

Table 3 Genes of significant two fold or more alteration of the expression level in mS100A4 knockdown endothelial MSS31 cells

\begin{tabular}{lll}
\hline Gene name & $\begin{array}{l}\text { Gene } \\
\text { symbol }\end{array}$ & $\begin{array}{l}\text { Fold } \\
\text { change }\end{array}$ \\
\hline $\begin{array}{l}\text { Downregulated gene } \\
\text { Resistin }\end{array}$ & retn & 4.8 \\
Fibroblast growth factor 18 & fgf18 & 4.6 \\
Aquaporin-1 & aqp1 & 2.9 \\
Mitogen-activated protein kinase & map3k5 & 2.2 \\
$\quad$ kinase kinase 5 & & \\
Thymus cell antigen & thy1 & 2.1 \\
Forkhead box 06 & foxo6 & 2.1 \\
Heparan sulfate 6-O-sulfotranseferase 1 & hs6st1 & 2.0 \\
Matrix metalloproteinase 3 & mmp3 & 1.7 \\
Upregulated gene & & \\
Cyclin-dependent kinase inhibitor 1A & cdkn1a & 3.2 \\
Thrombospondin 1 & thbs1 & 2.4 \\
Sprouty homolog 4 & spry4 & 2.4 \\
\hline
\end{tabular}

\section{Discussion}

Using B16BL6 tumor tissues little expressing S100A4, we stained tumor microvessels for CD31 and S100A4 and found that there are subpopulations of endothelial cells in tumors, S100A4-positive and -negative ones. This observation motivated us to examine a possible role of endothelial S100A4 by silencing it. The multiple angiogenesis assay including tube formation, adhesion, and migration analysis of endothelial cells clearly indicated that endothelial S100A4 plays a crucial role in angiogenesis. S100A4-positive endothelial cells in tumors may represent the ones primed for neoangiogenesis. A comparison of the gene expression profiles of siRNA-treated cells with those of untreated cells showed that endothelial S100A4 acts upstream of a variety of angiogenesis-related genes. These findings were confirmed in a xenograft tumor model, where intratumor administration of siRNA distinctly reduced tumor angiogenesis and growth.

In the present study, mouse siRNA was delivered in vivo using atelocollagen, a highly purified type I collagen with low immunogenicity. Atelocollagen forms nano-sized particles when mixed with oligonucleotides such as double stranded RNAs and DNAs via electrostatic binding, and is incorporated into cells by endocytosis [43, 44]. In xenografted tumor tissues, many cell types can take up the
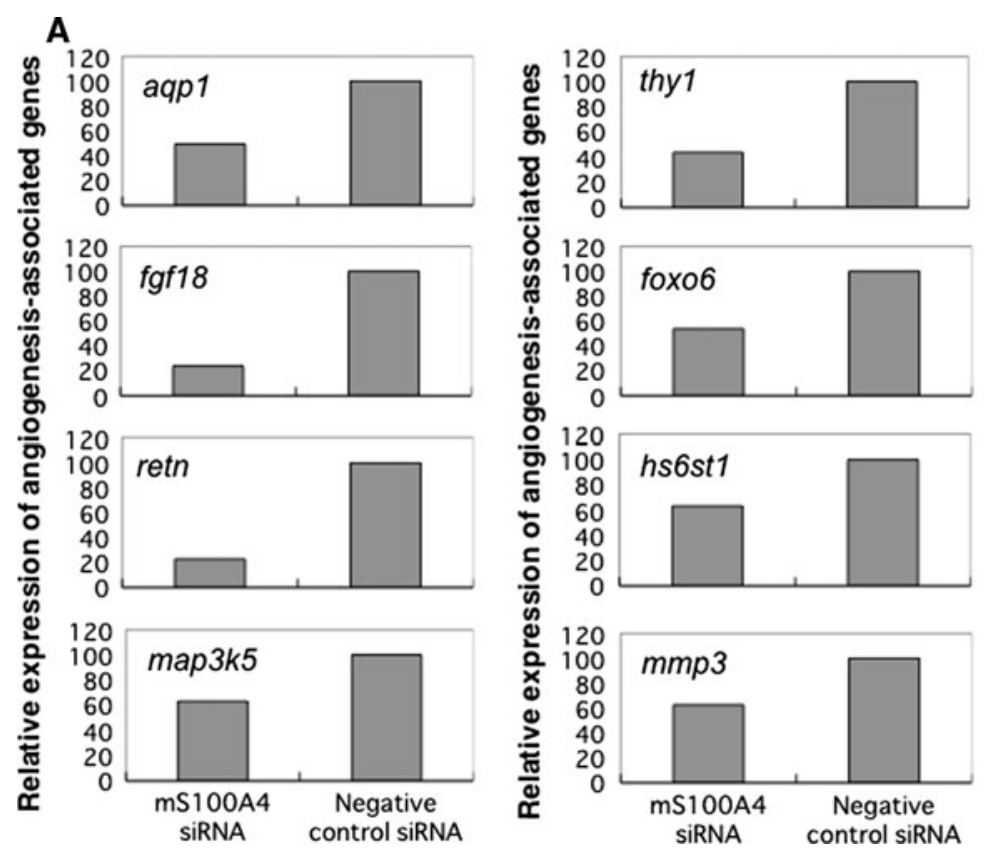

B

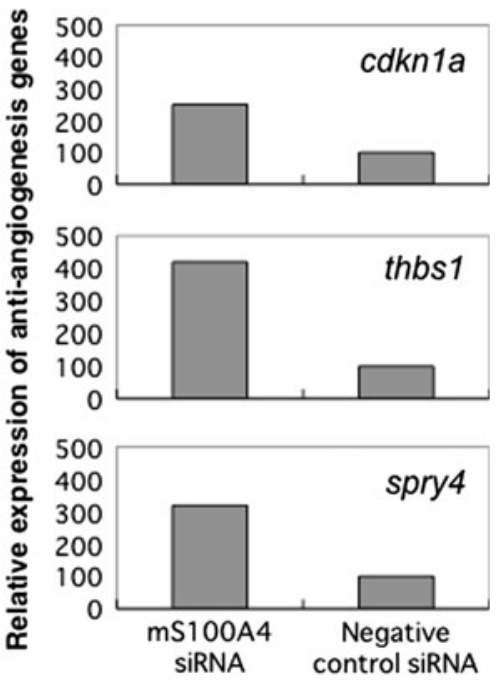

Fig. 6 Modulation of the expression of angiogenesis-related genes by S100A4 siRNA. Verification of microarray analysis via RT-PCR. RT-PCR analysis was performed under linear amplification conditions. The GAPDH gene was used as an internal control. a Genes in

mS100A4 knockdown cells with lower expression levels included angiogenesis-associated genes. b Genes in mS100A4 knockdown cells with higher expression levels included anti-angiogenesis genes 
complex, including human prostate cancer cells, endothelial cells and stromal cells. However, the specificity of the siRNA for mouse S100A4 suggests that the primary target of the S100A4 siRNA was the mouse vasculature.

Microarray analysis further confirmed the molecular mechanism of S100A4-mediated angiogenesis in endothelial cells. Significant changes in angiogenesis-promoting gene expression occurred in S100A4 siRNA-treated endothelial cells. Among the genes exhibiting altered expression levels, aqp 1 , map $3 k 5$, and $f g f l 8$ are highly expressed in tumor-associated blood vessels in several human tumors [45-48]. Furthermore, our results indicate that S100A4 may negatively regulate anti-angiogenic genes, such as $c d k n l a$, thbs 1 , and spry4. This means that S100A4 has a dual effect on angiogenesis-related gene expression: it up-regulates angiogenic genes and down-regulates anti-angiogenic ones, thereby determining the fate of endothelial cells in association with tumorigenesis. The biological significance of all these genes has been proven in vitro and in vivo analysis of angiogenesis in previous reports.

Our sequential observations revealed that mS100A4 knockdown induced apparent cell growth inhibition of MSS31 cells in a later stage after siRNA treatment. It suggests a possible role of S100A4 in regulating endothelial cell growth, which may, in part, account for a drastic inhibition of neoangiogenesis in mS100A4 siRNA-administered tumor. Further analysis is required to know whether S100A4 promotes growth and survival of neovascular endothelial cells.

In the human cancer xenograft model used in this study, only host S100A4 was targeted to explore the role of S100A4 in angiogenesis. However, S100A4 in tumor cells is also involved in invasion and metastasis. Therefore, it would be interesting to investigate whether administration of an agent that inhibits both mouse and human S100A4 could suppress the metastasis of xenografted human tumor cells in immuno-compromised mice. If suppression occurs, it would suggest that inhibition of S100A4 could reduce tumor angiogenesis and by inference, tumor metastatic ability, which would have important implications for the development of cancer therapeutics. Furthermore, it would underscore the advantages of S100A4 inhibition over conventional angiogenesis factor/receptor inhibition. Studies are currently under way to develop such agents.

In conclusion, the present results show the importance of endothelial S100A4 expression in tumor angiogenesis. As the generation of a new vascular supply is causally involved in the progression of the majority of solid tumors, siRNA-mediated inhibition of endothelial S100A4 could provide an effective anti-tumor RNAi medicine. Thus, the development of inhibitors targeting endothelial S100A4 could represent a promising approach for effective antiangiogenesis and anti-metastasis therapy.
Acknowledgments We sincerely thank Dr. S. Mori, emeritus Professor of the Institute of Medical Science, The University of Tokyo for the initiation of this study. This work was supported in part by a Grant-in-Aid for the Third-Term Comprehensive 10-year Strategy for Cancer Control, and the Program for Promotion of Fundamental Studies in Health Sciences of the National Institute of Biomedical Innovation (NiBio). This work was also supported by a Grant-in-Aid for Japan Arteriosclerosis Research Foundation.

Conflict of interest The authors have declared that no competing interests exist.

Open Access This article is distributed under the terms of the Creative Commons Attribution License which permits any use, distribution, and reproduction in any medium, provided the original author(s) and the source are credited.

\section{References}

1. Ebralidze A, Tulchinsky E, Grigorian M, Afanasyeva A, Senin V, Revazova E et al (1989) Isolation and characterization of a gene specifically expressed in different metastatic cells and whose deduced gene product has a high degree of homology to a $\mathrm{Ca}^{+}$-binding protein family. Genes Dev 3:1086-1093

2. Davies BR, O'Donnell M, Durkan GC, Rudland PS, Barraclough $\mathrm{R}$, Neal DE et al (2002) Expression of S100A4 protein is associated with metastasis and reduced survival in human bladder cancer. J Pathol 196:292-299

3. Platt-Higgins AM, Renshaw CA, West CR, Winstanley JH, De Silva Rudland S, Barraclough R et al (2000) Comparison of the metastasis-inducing protein S100A4 (p9ka) with other prognostic markers in human breast cancer. Int J Cancer 89:198-208

4. Rosty C, Ueki T, Argani P, Jansen M, Yeo CJ, Cameron JL et al (2002) Overexpression of S100A4 in pancreatic ductal adenocarcinomas is associated with poor differentiation and DNA hypomethylation. Am J Pathol 160:45-50

5. Rudland PS, Platt-Higgins A, Renshaw C, West CR, Winstanley $\mathrm{JH}$, Robertson L et al (2000) Prognostic significance of the metastasis-inducing protein $\mathrm{S} 100 \mathrm{~A} 4(\mathrm{p} 9 \mathrm{Ka})$ in human breast cancer. Cancer Res 60:1595-1603

6. Takenaga K, Nakanishi H, Wada K, Suzuki M, Matsuzaki O, Matsuura A et al (1997) Increased expression of S100A4, a metastasis-associated gene, in human colorectal adenocarcinomas. Clin Cancer Res 3:2309-2316

7. Yonemura Y, Endou Y, Kimura K, Fushida S, Bandou E, Taniguchi $\mathrm{K}$ et al (2000) Inverse expression of S100A4 and E-cadherin is associated with metastatic potential in gastric cancer. Clin Cancer Res 6:4234-4242

8. Lukanidin E, Georgiev G (1996) Metastasis-related mts1 gene. In: Günthert U, Birchmeier W (eds) Current topics in microbiology and immunology: attempts to understand metastasis formation, vol 213/II. Springer, Berlin, pp 171-195

9. Ambartsumian NS, Grigorian MS, Larsen IF, Karlstrøm O, Sidenius N, Rygaard J et al (1996) Metastasis of mammary carcinomas in GRS/A hybrid mice transgenic for the mts1 gene. Oncogene 13:1621-1630

10. Davies MP, Rudland PS, Robertson L, Parry EW, Jolicoeur P, Barraclough R (1996) Expression of the calcium-binding protein S100A4 (p9Ka) in MMTV-neu transgenic mice induces metastasis of mammary tumours. Oncogene 13:1631-1637

11. Barraclough R (1998) Calcium-binding protein S100A4 in health and disease. Biochim Biophys Acta 1998(1448):190-199

12. Grum-Schwensen B, Klingelhofer J, Berg CH, El-Naaman C, Grigorian M, Lukanidin E et al (2005) Suppression of tumor 
development and metastasis formation in mice lacking the S100A4(mts1) gene. Cancer Res 65:3772-3780

13. Hua J, Chen D, Fu H, Zhang R, Shen W, Liu S et al (2010) Short hairpin RNA-mediated inhibition of S100A4 promotes apoptosis and suppresses proliferation of BGC823 gastric cancer cells in vitro and in vivo. Cancer Lett 292:41-47

14. Zhang G, Li M, Jin J, Bai Y, Yang C (2011) Knockdown of S100A4 decreases tumorigenesis and metastasis in osteosarcoma cells by repression of matrix metalloproteinase-9. Asian Pac J Cancer Prev 12:2075-2080

15. Takenaga K, Nygren J, Zelenina M, Ohira M, Iuchi T, Lukanidin E, Sjöquist M, Kozlova EN (2007) Modified expression of Mts1/S100A4 protein in C6 glioma cells or surrounding astrocytes affects migration of tumor cells in vitro and in vivo. Neurobiol Dis 25:455-463

16. Saleem M, Kweon MH, Johnson JJ, Adhami VM, Elcheva I, Khan $\mathrm{N}$ et al (2006) S100A4 accelerates tumorigenesis and invasion of human prostate cancer through the transcriptional regulation of matrix metalloproteinase 9. Proc Natl Acad Sci USA 103:14825-14830

17. Li N, Song MM, Chen XH, Liu LH, Li FS (2012) S100A4 siRNA inhibits human pancreatic cancer cell invasion in vitro. Biomed Environ Sci 25:465-470

18. Chen D, Zheng XF, Yang ZY, Liu DX, Zhang GY, Jiao XL, Zhao H (2012) S100A4 silencing blocks invasive ability of esophageal squamous cell carcinoma cells. World J Gastroenterol 18:915-922

19. Ambartsumian N, Klingelhöfer J, Grigorian M, Christensen C, Kriajevska M, Tulchinsky E et al (2001) The metastasis-associated Mts1(S100A4) protein could act as an angiogenic factor. Oncogene 20:4685-4695

20. Schmidt-Hansen B, Ornås D, Grigorian M, Klingelhöfer J, Tulchinsky E, Lukanidin E et al (2004) Extracellular S100A4(mts1) stimulates invasive growth of mouse endothelial cells and modulates MMP-13 matrix metalloproteinase activity. Oncogene 23:5487-5495

21. Schmidt-Hansen B, Klingelhöfer J, Grum-Schwensen B, Christensen A, Andresen S, Kruse C, Hansen T et al (2004) Functional significance of metastasis-inducing S100A4(Mts1) in tumorstroma interplay. J Biol Chem 279:24498-24504

22. Endo H, Takenaga K, Kanno T, Satoh H, Mori S (2002) Methionine aminopeptidase 2 is a new target for the metastasis-associated protein, S100A4. J Biol Chem 277:26396-26402

23. Takenaga K, Nakamura Y, Sakiyama S, Hasegawa Y, Sato K, Endo H (1994) Binding of pEL98 protein, an S100-related calcium-binding protein, to nonmuscle tropomyosin. J Cell Biol 124:757-768

24. Yanai N, Satoh T, Obinata M (1991) Endothelial cells create a hematopoietic inductive microenvironment preferential to erythropoiesis in the mouse spleen. Cell Struct Funct 16:87-93

25. Namba K, Abe M, Saito S, Satake M, Ohmoto T, Watanabe T, Sato $\mathrm{Y}$ (2000) Indispensable role of the transcription factor PEBP2/CBF in angiogenic activity of a murine endothelial cell MSS31. Oncogene 19:106-114

26. Takahashi T, Yamaguchi S, Chida K, Shibuya M (2001) A single autophosphorylation site on KDR/Flk-1 is essential for VEGF-Adependent activation of PLC-gamma and DNA synthesis in vascular endothelial cells. EMBO J 20:2768-2778

27. Takeshita F, Minakuchi Y, Nagahara S, Honma K, Sasaki H, Hirai K et al (2005) Efficient delivery of small interfering RNA to bone-metastatic tumors by using atelocollagen in vivo. Proc Natl Acad Sci USA 102:12177-12182

28. Fidler IJ (1973) Selection of successive tumour lines for metastasis. Nat New Biol 1242:148-149

29. Taniguchi S, Kawano T, Kakunaga T, Baba T (1986) Differences in expression of a variant actin between low and high metastatic B16 melanoma. J Biol Chem 261:6100-6106
30. Takenaga K, Nakamura Y, Endo H, Sakiyama S (1994) Involvement of S100-related calcium-binding protein pEL98 (or mts1) in cell motility and tumor cell invasion. Jpn J Cancer Res 85:831-839

31. Bussolino F, Di Renzo MF, Ziche M, Bocchietto E, Olivero M, Naldini L et al (1992) Hepatocyte growth factor is a potent angiogenic factor which stimulates endothelial cell motility and growth. J Cell Biol 119:629-641

32. Saadoun S, Papadopoulos MC, Hara-Chikuma M, Verkman AS (2005) Impairment of angiogenesis and cell migration by targeted aquaporin-1 gene disruption. Nature 434:786-792

33. Antoine M, Wirz W, Tag CG, Gressner AM, Wycislo M, Müller R et al (2006) Fibroblast growth factor 16 and 18 are expressed in human cardiovascular tissues and induce on endothelial cells migration but not proliferation. Biochem Biophys Res Commun 346:224-233

34. Mu H, Ohashi R, Yan S, Chai H, Yang H, Lin P et al (2006) Adipokine resistin promotes in vitro angiogenesis of human endothelial cells. Cardiovasc Res 70:146-157

35. Izumi Y, Kim-Mitsuyama S, Yoshiyama M, Omura T, Shiota M, Matsuzawa A et al (2005) Important role of apoptosis signalregulating kinase 1 in ischemia-induced angiogenesis. Arterioscler Thromb Vasc Biol 25:1877-1883

36. Jurisic G, Iolyeva M, Proulx ST, Halin C, Detmar M (2010) Thymus cell antigen 1 (Thy1, CD90) is expressed by lymphatic vessels and mediates cell adhesion to lymphatic endothelium. Exp Cell Res 316:2982-2992

37. Maiese K, Hou J, Chong ZZ, Shang YC (2009) A fork in the path: developing therapeutic inroads with FoxO proteins. Oxid Med Cell Longev 2:119-129

38. Backen AC, Cole CL, Lau SC, Clamp AR, McVey R, Gallagher JT et al (2007) Heparan sulphate synthetic and editing enzymes in ovarian cancer. Br J Cancer 96:1544-1548

39. Spurbeck WW, Ng CY, Strom TS, Vanin EF, Davidoff AM (2002) Enforced expression of tissue inhibitor of matrix metalloproteinase- 3 affects functional capillary morphogenesis and inhibits tumor growth in a murine tumor model. Blood 100:3361-3368

40. Lee S, Bui Nguyen TM, Kovalenko D, Adhikari N, Grindle S, Polster SP et al (2010) Sprouty1 inhibits angiogenesis in association with up-regulation of p21 and p27. Mol Cell Biochem 338:255-261

41. Iruela-Arispe ML, Lombardo M, Krutzsch HC, Lawler J, Roberts DD (1999) Inhibition of angiogenesis by thrombospondin-1 is mediated by 2 independent regions within the type 1 repeats. Circulation 100:1423-1431

42. Cabrita MA, Christofori G (2008) Sprouty proteins, masterminds of receptor tyrosine kinase signaling. Angiogenesis 11:53-62

43. Honma K, Iwao-Koizumi K, Takeshita F, Yamamoto Y, Yoshida T, Nishio K et al (2008) RPN2 gene confers docetaxel resistance in breast cancer. Nat Med 14:939-948

44. Ochiya T, Takahama Y, Nagahara S, Sumita Y, Hisada A, Itoh $\mathrm{H}$ et al (1999) New delivery system for plasmid DNA in vivo using atelocollagen as a carrier material: the minipellet. Nat Med 5:707-710

45. Hayashi Y, Edwards NA, Proescholdt MA, Oldfield EH, Merrill MJ (2007) Regulation and function of aquaporin-1 in glioma cells. Neoplasia 9:777-787

46. Loreto C, Galanti C, Almeida LE, Leonardi R, Pannone G, Musumeci $G$ et al (2012) Expression and localization of aquaporin-1 in temporomandibular joint disc with internal derangement. J Oral Pathol Med 41:642-647

47. Horcajadas JA, Mínguez P, Dopazo J, Esteban FJ, Domínguez F, Giudice LC et al (2008) Controlled ovarian stimulation induces a functional genomic delay of the endometrium with potential clinical implications. J Clin Endocrinol Metab 93:4500-4510

48. Sonvilla G, Allerstorfer S, Stättner S, Karner J, Klimpfinger M, Fischer $\mathrm{H}$ et al (2008) FGF18 in colorectal tumour cells: autocrine and paracrine effects. Carcinogenesis 29:15-24 